\title{
Advances in Assessment of Geothermal Resources of South America
}

\author{
Fabio Pinto Vieira, Valiya Mannathal Hamza \\ Observatório Nacional/MCT, Rio de Janeiro, Brazil \\ Email: hamza@on.br
}

Received 4 September 2014; revised 11 October 2014; accepted 30 October 2014

Copyright (C) 2014 by authors and Scientific Research Publishing Inc.

This work is licensed under the Creative Commons Attribution International License (CC BY).

http://creativecommons.org/licenses/by/4.0/

(c) (i) Open Access

\begin{abstract}
Updated data for 1417 localities have been assembled for purposes of assessments of geothermal resources in South America. Analyses of these data sets have allowed improved estimates of geothermal resource base and recoverable resources for thirteen countries in the continent. The results obtained have also allowed identification of more than 20 crustal blocks where the resource base per unit area (referred to the accessible depth limit of $3 \mathrm{~km}$ ) is in the range of 100 to 1000 Giga Joules, while the recoverable resources per unit area are in the range of 1 to 100 Giga Joules. Most of the high temperature resources occur within regions of recent tectonic activities in southern and central Chile, highlands regions in Bolivia, and several localities along the magmatic arc covering western Ecuador, central volcanic belt of Colombia and northern Venezuela. In addition, isolated pockets of geothermal resources have been identified along the eastern Andean belt of Peru. There are indications of occurrence of medium and low temperature geothermal resources at depths of 1 to $3 \mathrm{~km}$ in several regions in the eastern sectors of the continent, mainly in the northeastern and central parts of Brazil. In addition, considerable progress has been made in assessments of low temperature resources associated with deep fracture systems in Precambrian terrains. Progress has also been achieved in assessment of low temperature resources in deep aquifers of Paleozoic sedimentary basins. The results of such estimates are currently being considered for planning large-scale exploitation of the Guarani aquifer system, which spans over large areas of western Uruguay, northern Argentina and southern Brazil.
\end{abstract}

\section{Keywords}

Geothermal Resources, Resource Base, Recoverable Resources, South America

\section{Introduction}

Assessment of resources constitutes an important part of activities not only in the initial stages of geothermal 
exploration (reconnaissance and feasibility studies) but also during advanced stages of exploitation and development. Compilations of data sets on subsurface temperatures, heat flux, thermal spring discharges and geotectonic characteristics of subsurface strata are essential ingredients in assessments of geothermal resources. Depending on data density, the assessments may be carried out either on regional or on local scales. Evaluations of geothermal resources have also been carried out on continental [1] [2] and global scales (see for example [3]-[5]).

Several attempts have been made in the past few decades for assessments of geothermal resources on local scales in specific regions of South American continent. The results of some of such assessments have been reported as parts of updates of geothermal project works in Argentina [6]-[9], Bolivia [10], Brazil [11]-[16], Chile [17]-[19], Colombia [20] [21], Ecuador [22]-[24], Peru [25] [26] and Venezuela [27] [28]. A major weakness of these earlier studies is that resource estimates are based predominantly on information gathered on near surface geothermal manifestations and compilations on subsurface temperature data from geothermal areas. Very few attempts seem to have been made in incorporating complementary information on regional geologic and geophysical characteristics of subsurface strata in resource assessments.

Reference [1] presented a summary of geothermal development projects in South and Central America. Reference [2] presented a new approach in which crustal structure and geothermal data averaged over $2 \times 2$ degree grid elements were employed in assessment of geothermal resource base for the South American continent. The results revealed that blending geothermal and crustal structure data sets did indeed lead to improvements in quality of resource assessments. However, averaging of temperature and heat flow data over $2 \times 2$ cells lead to considerable loss of spatial resolution in resource assessments. In the present work, we adopt an approach which avoids smoothing of near surface temperature and heat flow data but takes into take into consideration the influence of regional lithologic and hydrologic characteristics of subsurface strata that have direct bearing on local variations of geothermal resources. It is argued that the hybrid approach in integration of geothermal and crustal data sets is capable of providing better insights into the specific features in the occurrence and distribution of resources on regional scales.

\section{Sources of Data}

The sources of data assembled for the present work may be considered as falling into two main groups, designated here as: Near-Surface Geothermal and Deep Crustal Structure. The Near-Surface Geothermal group is comprised of observational data sets on temperatures and thermal gradients, heat flow, physical properties and thermal springs. The Deep Crustal Structure group is comprised of data sets on thicknesses, density and seismic velocities of the main crustal layers. Given below are brief descriptions of these two groups of data sets.

\subsection{Near-Surface Geothermal}

The temperature and heat flow data and related information on geothermal systems, employed in the present work, are derived from the geothermal database for South America, maintained by the National Observatory, Brazil. Major difficulties in organizing this database arise from large variations in the quality of observational data and limitations in the availability of basic information on subsurface strata. Nevertheless, information that compose the present compilations have been useful in determining representative values of temperature gradient and heat flow over large parts of the continental area. Systematic updates of compilations and improvements in the database for the grid system have been useful in the past in deriving heat flow maps of the South American continent [29] [30]. Observational data are currently available for slightly more than $50 \%$ of such grid elements.

This database has recently been updated with temperature gradient and heat flow values for several new localities. These include the Neuquina sedimentary basin in western Argentina, system of tectonic basins (Catatumba, Cusiana, Cupiaga, Eastern Cordillera, Llanos, Magdalena and Putumayo) in the Andean region of Colombia, coastal areas of eastern Brazil (in the states of Ceará, Rio Grande do Norte, Bahia and Espirito Santo) and Archean areas in the São Francisco craton in central Brazil.

At this point, some comments on the characteristics of data compiled for the present work are in order. Values of geothermal gradients and heat flow reported in the present work have been obtained using procedures specific to the different experimental methods employed in field and laboratory works. Following the practice adopted in previous works [29] [30] the methods in determinations of geothermal gradient are designated with abbreviations CVL, MGT, BHT, CBT, AQT and GCL. The CVL method refers to the procedure for calculating geothermal gradients derived from results of incremental temperature logs of undisturbed boreholes [31]. The MGT 
method refers to the procedure used for determining gradients based on measurements in underground mine galleries [32], while BHT method refers to gradient values derived from bottom-hole temperature measurements carried out by oil industry in exploration wells [33]. The CBT method is a variant of the BHT method used for determining gradient values based on precision temperature measurements in undisturbed sections at the bottom parts of boreholes [34]. Similarly, AQT method refers to a procedure developed for determining temperature gradients in flowing wells [35]. Estimates of heat flow at sites of thermal springs have also been made making use of methods, designated here as GCL, which are variations of the procedures proposed initially by [36] [37].

For areas where observational data are not available, values of temperature gradients and heat flow may be estimated using empirical heat flow-age relations, as has been done in global heat flow data analysis by [38][41]. A variation of this method was considered by [2], in which estimated values of heat flow geothermal gradients are derived from spherical harmonic coefficients of the composite global heat flow data set. In the present work, we have adopted an updated version of the procedure proposed by [2] in deriving estimates of temperature gradients for $2^{\circ} \times 2^{\circ}$ grid system of the South American continent.

The maps of Figure 1 illustrate the distribution of experimental and estimated values. In this figure, the left panel indicates distribution of localities of geothermal data while the right panel is a discretized representation of the $2^{\circ} \times 2^{\circ}$ grid system of data distribution. Color codes in the right panel indicate grid elements with observational data, grid elements in white color indicate areas with estimated values. Note that data density is relatively better in the southwestern and northeastern parts of the continent.

\subsection{Deep Crustal Structure}

The data sets on deep crustal structure have been considered in the present work as a convenient means of improving the framework for geothermal resource assessment of South America. For this purpose, use has been made of crustal data compilations [42] [43]. Following the approach adopted in these earlier works, the crust is assumed to be composed of five sequential layers, classified as: soft sediments, hard sediments, upper crust, middle crust and lower crust. The compilations of [42] [43] provides mean values of the thickness of the crustal layers for $2^{\circ} \times 2^{\circ}$ grid elements. Mapsillustrating the regional variations in the thicknesses of the sedimentary layers and of the upper crust in South America have been derived [2]. Soft sediments are present as layers with thickness less than $500 \mathrm{~m}$ in large parts of the Precambrian cratonic areas and in the Andean ranges [2] [42]. However, in most parts of the Pre-Cordilleran and Paleozoic basins the thicknesses of sediment layers are in the
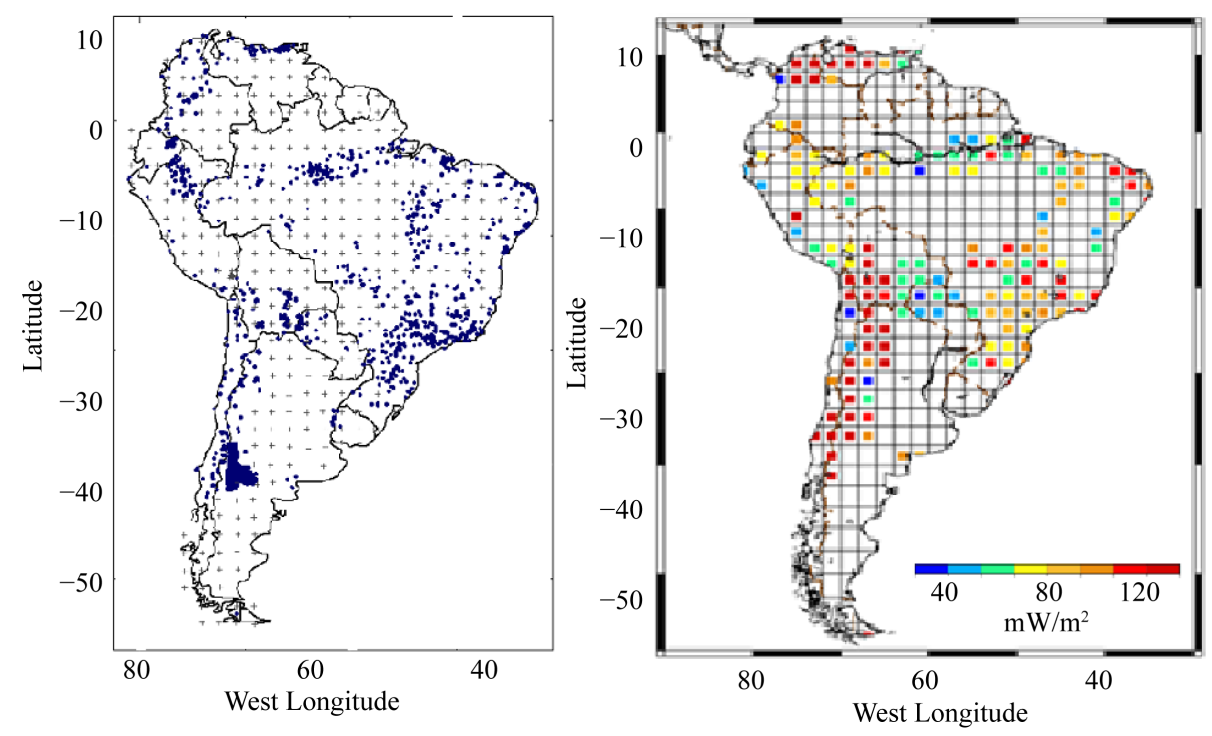

Figure 1. Illustrations of geothermal data coverage for South America. The left panel indicates distribution of localities of geothermal data (blue dots indicate observational data; crosses indicate estimated values). The right panel is a discretized representation of the $2^{\circ} \times 2^{\circ}$ grid system of data distribution. Color codes indicate grid elements with observational data. White grids indicate areas with estimated values. See text for details. 
range of 0.5 to $1.5 \mathrm{~km}$. The exceptions are the northern parts of Colombia and Venezuela, where thicknesses of sedimentary layers are in excess of $1.5 \mathrm{~km}$. In the case of hard sedimentary layers the regions with thicknesses greater than $2 \mathrm{~km}$ occur along an arc shaped belt extending from Venezuela to south Brazil. It is practically absent in Precambrian cratonic areas. The upper crustal layer reaches up to values of $24 \mathrm{~km}$ in the central Andean region. Thickness values are in the range of 12 to $20 \mathrm{~km}$ in the central parts of the continent. Both the northern and southern extremes are characterized by relatively thin upper crust, with thicknesses less than $12 \mathrm{~km}$.

Integrated analysis of geothermal and crustal structure data sets has been useful in determining vertical distributions of temperatures in the upper crust. Such calculations are based on a simple one-dimensional heat conduction model, which incorporates the effects of depth-dependent variations in thermal conductivity and radiogenic heat production. For layered media with constant thermal properties the relation for temperature $\left(T_{i}\right)$ as a function of depth $\left(z_{i}\right)$ is:

$$
T(z)=T_{0 i}+\frac{q_{0 i}-A_{0 i} D_{i}^{2}}{\lambda_{i}} z+\frac{A_{0 i} D_{i}^{2}}{\lambda_{i}}\left[1-\mathrm{e}^{-z_{i} / D_{i}}\right]
$$

where $T_{0 i}$ is the surface temperature, $q_{0 i}$ the surface heat flux, $A_{0 i}$ radiogenic heat productivity and $\lambda_{i}$ the thermal conductivity of the $i^{\text {th }}$ element. This model has been employed in calculating crustal temperature distributions and in deriving maps of basal temperatures of the principal layers. According to results of [2] temperatures in excess of $80^{\circ} \mathrm{C}$ at the base of soft sediments occur only in northern Venezuela, highlands region of central Andean cordillera and northern Chile. In most of the remaining regions, it is in the range of $40^{\circ} \mathrm{C}$ to $60^{\circ} \mathrm{C}$. In the case of hard sediments the basal temperatures in excess of $80^{\circ} \mathrm{C}$ are found to occur in several localities lying along an arc shaped belt extending from northern Venezuela to central Brazil, passing through southeast Ecuador and highlands of Bolivia. Temperatures of less than $80^{\circ} \mathrm{C}$ are found along the eastern parts of the continent. In the case of upper crust, temperature calculations were carried out for a set of thermal conductivity values representative of the main geologic formations in the continent. Such procedures introduce some degree of uncertainty in model results. However, the magnitudes errors involved are likely to be less than the uncertainties associated with errors in gradient and heat flow values. Basal temperatures in excess of $300^{\circ} \mathrm{C}$ are found along most of the Andean ranges. Surprisingly the upper crust in the southern cordillera in Chile is characterized by basal temperatures lower than $250^{\circ} \mathrm{C}$. In the eastern parts of the continent, basal temperatures in excess of $300^{\circ} \mathrm{C}$ are found to occur in the northeastern coastal region of Brazil, and also along a southeast-northwest trending belt between the northern part of the state of Mato Grosso and northern parts of the state of Rio de Janeiro.

\section{Methods Employed in Resource Estimates}

The resource base calculations were carried out following the methodology proposed in earlier studies (see [44], also [1]-[5]). Volumetric method was considered adequate for the present purpose. In the terminology proposed by [44] the resource base (RB) is considered as the excess thermal energy in the layer up to a depth of $10 \mathrm{~km}$, the reference temperature value for resource calculations being the mean annual surface temperature. In gridded data sets the resource base $\left(Q_{R B i}\right)$ for the $i^{\text {th }}$ cell, of thickness $d_{i}$, associated with the temperature distribution given by Equation (1), is calculated using the relation:

$$
Q_{R B i}=\rho_{i} C_{p i} A_{i} d_{i}\left(T_{i}-T_{0 i}\right)
$$

where $\rho_{i}$ is the average density, $c_{p i}$ the specific heat, $A_{i}$ the area of the cell, $T_{i}$ the bottom temperature of the cell and $T_{0 i}$ upper surface temperature. It is common practice to designate last factor on the right hand side of equation (2) as the "excess temperature". The relation for "excess temperature" $(\Delta T)$ over the mean surface temperature is given by the relation:

$$
\Delta T=\frac{q_{0}}{k} d-\frac{A_{0 r a d} d^{2}}{2 k}\left(1-\mathrm{e}^{-z / D}\right)
$$

where $q_{0}$ the surface heat flux, $A_{0}$ radiogenic heat productivity and $k$ the thermal conductivity. The values of $A_{0 i}$ is derived from empirical relations [45] relating crustal seismic velocities with radiogenic heat productivity.

Recoverable resource (RR) is usually defined as that part of the resource base associated with pore fluids that can be extracted using current technology (see [44], also [1]-[5]). In areas of positive geothermal gradients, temperatures of the rock matrix and the pore fluids increase with depth. However, values of porosity and per- 
meability of most common rocks decrease with depth, which imply a corresponding decrease in quantity of circulating fluids in deeper levels. The nature of opposing roles of temperature and porosity variations with depth can be understood by considering the relation for total geothermal resource $(Q)$ of a volume element (of area $A$ and thickness $h$ ) with rock temperature $T_{r}$ and porosity $\phi$ :

$$
Q=\left[\phi C_{f}+(1-\phi) C_{r}\right]\left[T_{r}-T_{0}\right] A h
$$

where $C_{f}$ and $C_{r}$ are the heat capacities of the fluid and rock matrix respectively. The variation of $T_{r}$ with depth $z$ depends on the local value of geothermal gradient $(\Gamma)$. The variation of porosity $\phi$ with depth $z$ is usually represented by a relation of the type:

$$
\phi=\phi_{0} \mathrm{e}^{-z / \Pi}
$$

where $\Pi$ is the logarithmic decrement of porosity with depth. The substitution of Equation (5) in Equation (4) leads to:

$$
Q=(z \Gamma A h)\left[\phi_{0} \mathrm{e}^{-z / \Pi} C_{f}\right]+(z \Gamma A h)\left[\left(1-\phi_{0} \mathrm{e}^{-z / \Pi}\right) C_{f}\right]
$$

It is simple to note that the first term in Equation (6) represents the recoverable resource (RR) while the second term represents the resource associated with the rock matrix (RM). The sum of RR and RM represents the resource base (RB). Numerical simulations with representative estimates of the main parameters in Equation (6) indicate that maximum value of recoverable resource occurs in the depth range of 2500 to 3500 meters. Hence, for purposes of the present work, the estimates of resource base and recoverable resources have been set to a reference depth limit of $3 \mathrm{~km}$. Mean values of porosity adopted for the main rock types are 0.25 (soft sediments), 0.15 (hard sediments), 0.1 (fracture zones) and 0.05 (igneous and metamorphic rocks).

\section{Results of Resource Assessments}

In comparative analysis of spatial distributions, it is convenient to work with values of resources per unit area. Such values are designated here as RBUA (resource base per unit area) and RRUA (recoverable resource per unit area) respectively. The resource estimates (RBUA and RRUA) are available for 1771 sites in South America. Details of resource assessments specific to the thirteen countries of the South American continent are discussed in the following items.

\subsection{Argentina}

The estimates of geothermal resources for Argentina are based on data acquired in 289 localities. These include incremental temperature logs (CVL) at four sites [46] and results of aquifer temperature measurements (AQT) at additional six sites [7]-[9]. Also included are grid-averaged BHT values for 164 sites in the Neuquina basin, in the west central parts of Argentina. These latter ones are derived from geothermal gradient and heat flow values for 2941 oil wells, reported by [47]. In addition, results of geochemical methods (GCL) have been used deriving estimates of temperatures and resources at 58 sites [6]-[9] [29]. A major drawback of this data set is its highly uneven geographic distribution, with most of the data sites located along pre-cordilleran regions in the west. Data density is relatively poor in the Patagonian platform areas to the east. In an attempt to minimize the undesirable effects of this uneven distribution use has been made of estimated values for 56 sites in the eastern parts, derived from spherical harmonic expansion of global heat flow data [38]-[41]. The mean value of resource base is 352 GJ while the recoverable part of this resource base is 79 GJ.

Maps of regional distributions of the resource base (RBUA) and recoverable resources (RRUA) are illustrated respectively in the left and right panels of Figure 2. In these maps, the blue dots indicate locations of observational data while crosses indicate locations of estimated values, these latter ones derived from spherical harmonic expansion of global heat flow data [38]-[41]. Referring to the left panel it is simple to note that Pre-Cordilleran regions in general are characterized by occurrences of resource base with values higher than 200 GJ. These are indicated as yellow and red shaded areas in the left panel. On the other hand, the platform areas in the eastern parts are characterized by relatively low values of resource base. A similar trend can also be seen in the distribution of recoverable resources, illustrated in the right panel of Figure 2. In this case, the red shaded areas indicate locations of recoverable resources with values higher than $80 \mathrm{GJ}$. 

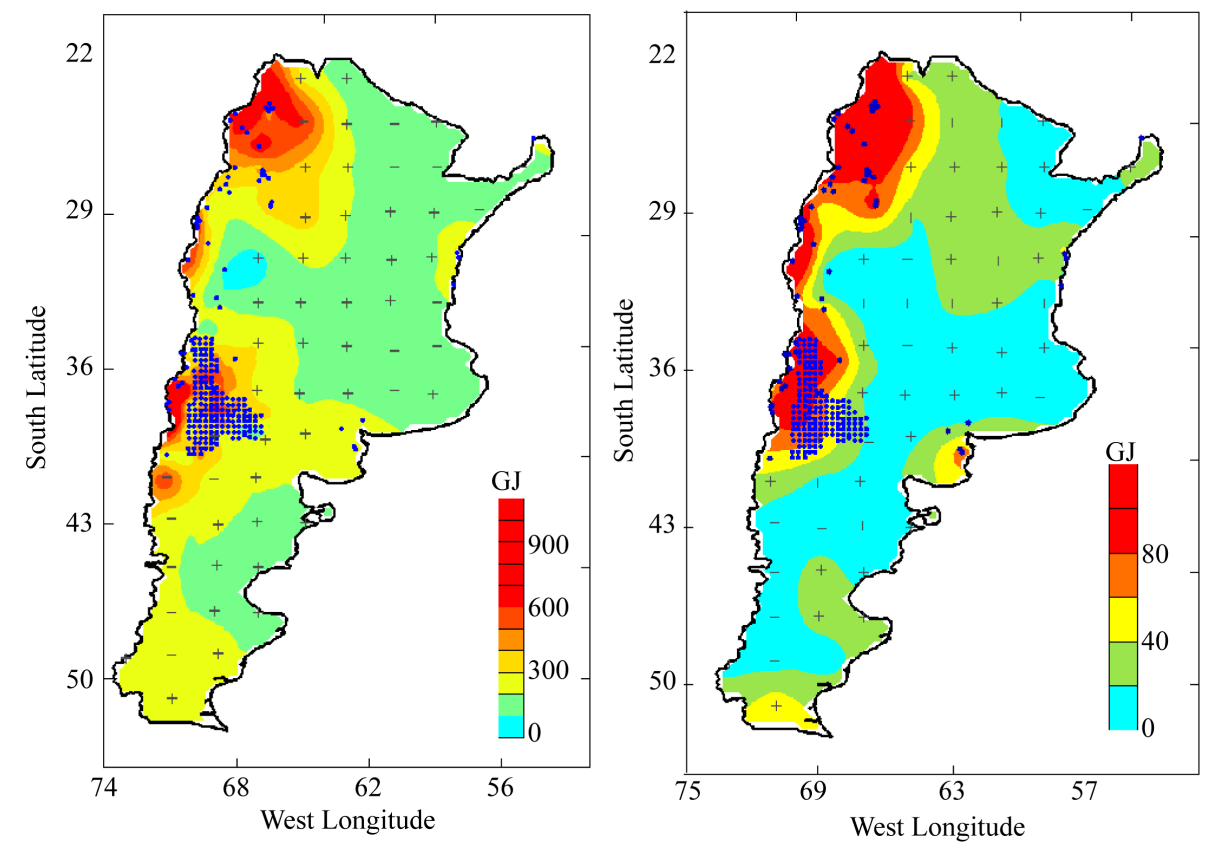

Figure 2. Distribution of geothermal resource base (left panel) and recoverable resources (right panel) in Argentina. Dots indicate locations of observational data and crosses indicate estimated values.

\subsection{Bolivia}

The estimates of geothermal resources for Bolivia are based on data acquired in 82 localities. These include results of incremental temperature logs (CVL) and underground mine measurements (MGT) at 20 sites and results of bottom-hole temperature method (BHT) at 32 sites [48] [49]. Most of the data are from the southern parts, while data density is relatively poor in the northern parts. In an attempt to minimize the undesirable effects of large-scale variations in data density, we have assigned estimated values for additional 30 sites. The mean value of resource base is $245 \mathrm{GJ}$ while the recoverable part of this resource base is estimated to be $41 \mathrm{GJ}$. The maps in the left and right panels of Figure 3 illustrate respectively the regional distributions of resource base per unit area (RBUA) and recoverable resource per unit area (RRUA). As in the previous case, the blue dots in these maps indicate locations of observational data while crosses indicate locations of estimated values, these latter ones derived from spherical harmonic expansion of global heat flow data [37]-[40].

Note that the southern parts of the highlands regions of Bolivia are characterized by occurrences of resource base with values higher than $300 \mathrm{GJ}$. These are indicated as orange and red shaded areas in the left panel. On the other hand, the eastern lowlands are characterized by relatively low values of resource base ( $<200 \mathrm{GJ})$. A similar trend can also be seen in the distribution of recoverable resources, illustrated in the right panel of Figure 3 . In this case, the red shaded areas indicate locations of recoverable resources with values higher than $80 \mathrm{GJ}$.

\subsection{Brazil}

The estimates of geothermal resources for Brazil are based on data acquired in 930 localities. These include results of incremental temperature logs (CVL) and underground mine measurements (MGT) at 109 sites and bottom-hole temperature measurements (BHT) at 301 sites. These data sets are derived from compilations discussed in earlier works [11]-[16] [29] [30]. Also included are data derived from results of geochemical methods (GCL) for 45 sites [37] and estimated values for 131 sites. Most of the data come from southeastern and northeastern parts, while the data density is poor in the north and northwestern parts. The mean value of resource base per unit area is $178 \mathrm{GJ}$ while the recoverable part of this resource base is estimated to be $10 \mathrm{GJ}$. The maps in the left and right panels of Figure 4 illustrate respectively the regional distributions of resource base (RBUA) and recoverable resource (RRUA), based on this data set. 

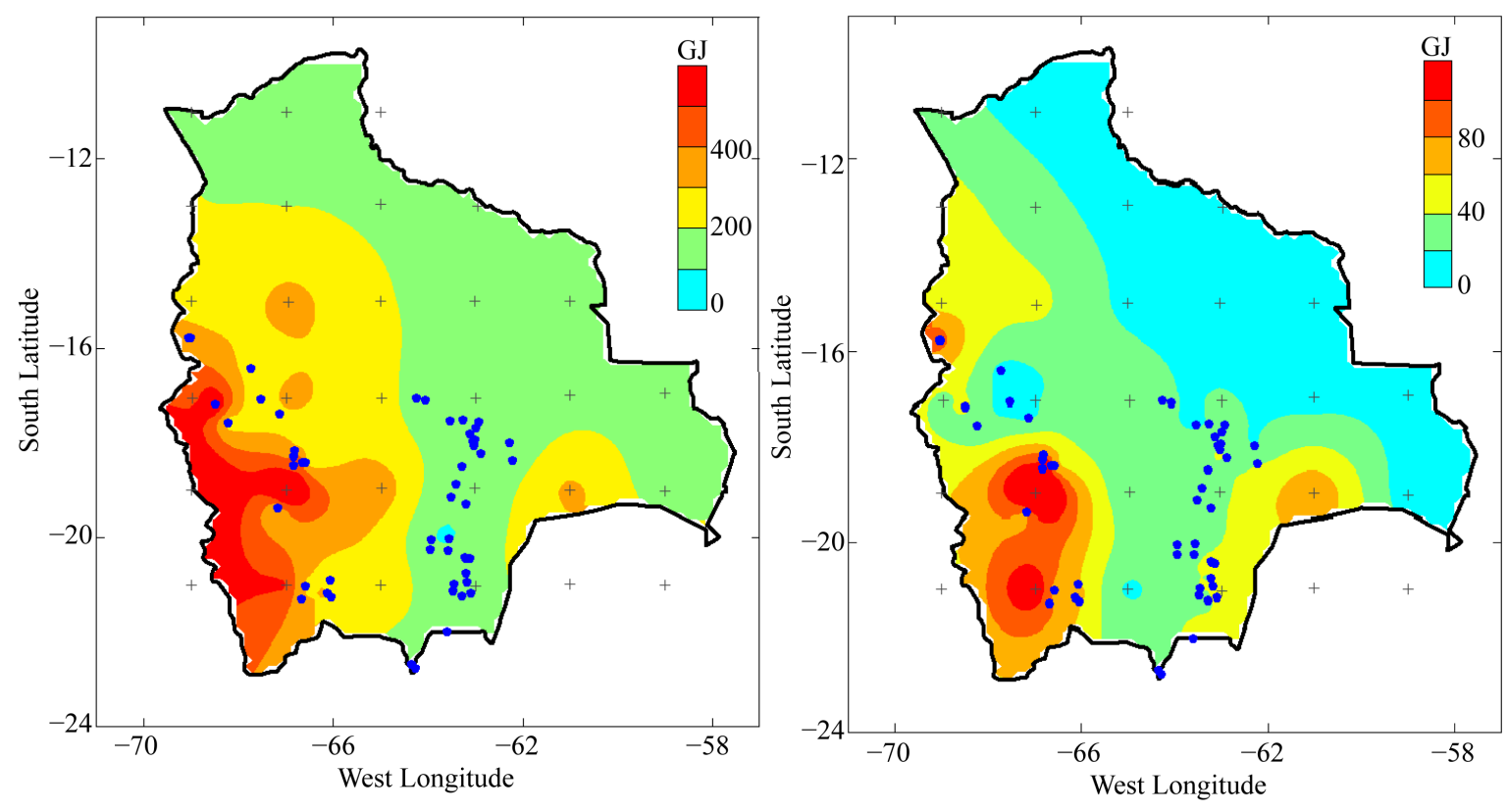

Figure 3. Distribution of geothermal resource base (left panel) and recoverable resources (right panel) in Bolivia. Dots indicate locations of observational data and crosses indicate estimated values.
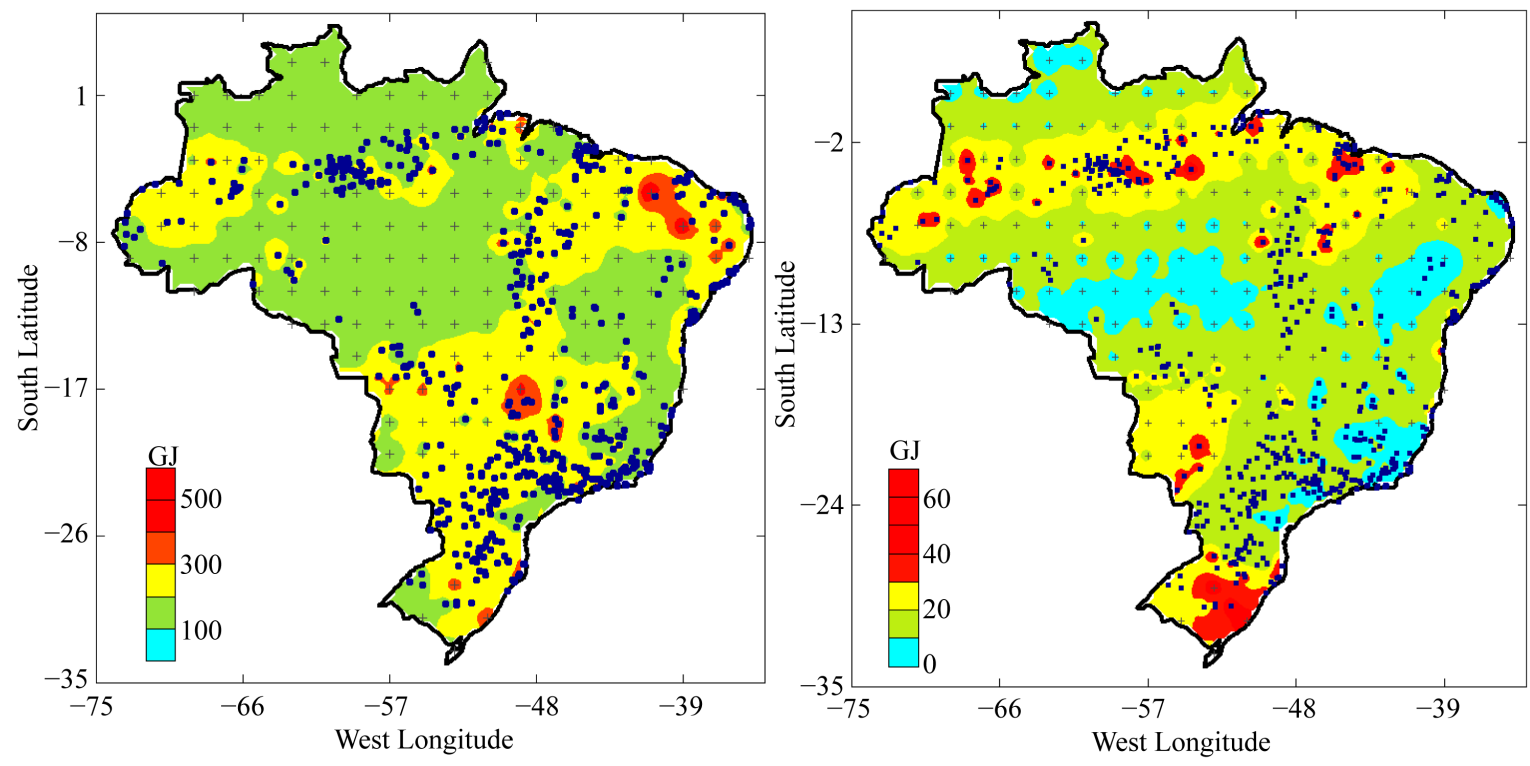

Figure 4. Distributions of geothermal resource base per unit area (left panel) and recoverable resources (right panel) in Brazil. Dots indicate locations of observational data and crosses indicate estimated values.

Note that resource base per unit area is higher than $200 \mathrm{GJ}$ in several parts of central and northeast Brazil. These are indicated as yellow and pink shaded areas in the left panel. The western and northern parts are characterized by relatively low values of resource base. A similar trend can also be seen in the distribution of recoverable resources, illustrated in the right panel of Figure 4. Recoverable resources with values higher than $30 \mathrm{GJ}$ are present in the southern state of Rio Grande do Sul. These are also present as isolated pockets along central parts of Amazon basins in the north, Parnaiba basin in the northeast and southwestern parts of Paraná basin in the south. Note that absence of sediment cover has led to low values of recoverable resources in northeast Brazil, even though resource base is high. 


\subsection{Chile}

The estimates of geothermal resources for Chile are based on data acquired in 72 localities. These include incremental temperature logs (CVL) and underground mine measurements (MGT) at 19 sites [50] and bottomhole temperature (BHT) and aquifer temperature (CBT) data at 2 sites [18]. Also included are results of geochemical methods (GCL) for 35 sites [17]-[19] [29] and estimated values for 16 sites. Most of the data are from southeastern and northeastern parts, while the data density is poor in the northwestern parts. The mean value of resource base is $499 \mathrm{GJ}$ while the recoverable part is estimated to be $61 \mathrm{GJ}$. The maps in the left and right panels of Figure 5 illustrate respectively the regional distributions of resource base (RBUA) and recoverable resource (RRUA). As in the previous case, the blue dots indicate locations of observational data while crosses indicate locations of estimated values, these latter ones derived from spherical harmonic expansion of global heat flow data [38]-[41].

Note that resource base is higher than 200 GJ all along the eastern parts, coincident with the locations of eastern and southern cordilleras in Chile. These are indicated as yellow and red shaded areas in the left panel. The northern and central parts of the eastern region of Chile are characterized by values of resource base higher than 400 GJ. The gaps in the occurrence of high resource base values are coincident also with regions where recent magmatic activities are absent. Also, regions of occurrence of high-temperature geothermal resources in Chile are contiguous with similar ones in western Argentina (see maps of Figure 2). These observations imply underlying connecting links between tectono-thermal processes in the deep crust and occurrence of high-temperature geothermal resources in South America. Similar trends can also be seen in the distributions of recoverable resources, illustrated in the right panel of Figure 5. Thus, recoverable resources with values higher than $30 \mathrm{GJ}$ are present only along a narrow belt in the northern and central parts of the eastern region in Chile.

Note that resource base is higher than $200 \mathrm{GJ}$ all along the eastern parts, coincident with the locations of eastern
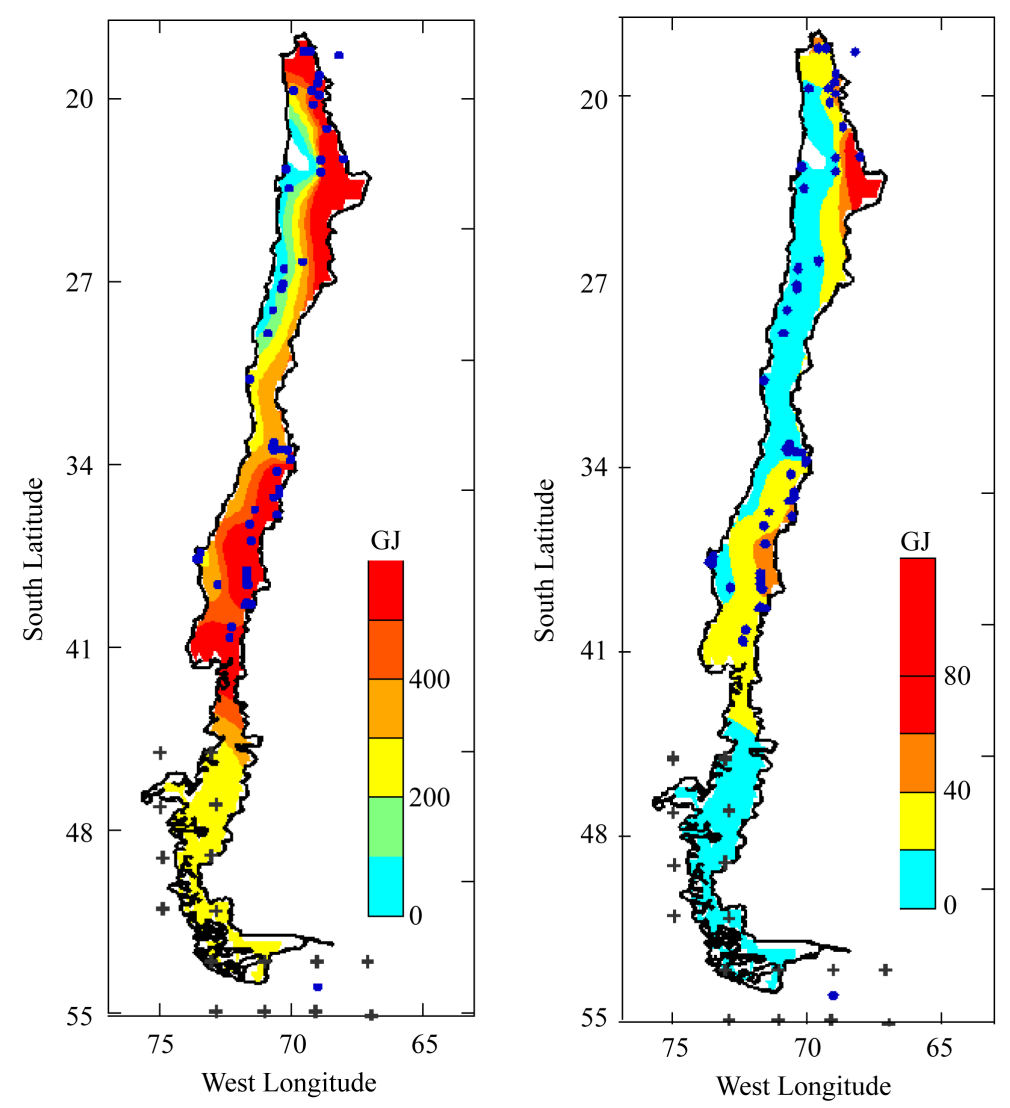

Figure 5. Distribution of geothermal resource base per unit area (left panel) and recoverable resources (right panel) in Chile. Dots indicate observational data and crosses indicate estimated values. 
and southern cordilleras in Chile. These are indicated as yellow and red shaded areas in the left panel. The northern and central parts of the eastern region of Chile are characterized by values of resource base higher than 400 GJ. The gaps in the occurrence of high resource base values are coincident also with regions where recent magmatic activities are absent. Also, regions of occurrence of high-temperature geothermal resources in Chile are contiguous with similar ones in western Argentina (see maps of Figure 2). These observations imply underlying connecting links between tectono-thermal processes in the deep crust and occurrence of high-temperature geothermal resources in South America. Similar trends can also be seen in the distributions of recoverable resources, illustrated in the right panel of Figure 5. Thus, recoverable resources with values higher than $30 \mathrm{GJ}$ are present only along a narrow belt in the northern and central parts of the eastern region in Chile.

\subsection{Colombia}

The estimates of geothermal resources for Colombia are based on data acquired in 66 localities and 18 grid averaged regions. These include data acquired using incremental temperature logs (CVL) for three sites [51] and use of geochemical methods (GCL) for 35 sites [20]. Results of bottom-hole temperature data, acquired in 4425 oil wells, have been regrouped into grid-averaged values for $15 \mathrm{sub}$ regions representing the main sedimentary basins in central Colombia [21]. These include basins of Caguan Vaupes (CAG), Catatumbo (CAT), Cauca Patia (CAU), Cesar Rancharia (CES), Choco (CHO), Eastern Ranges (COR), Guajira (GUA), Llanos (LLA), Lower Magdalena Valley (VIM), Middle Magdalena Valley (VMM), Putumayo (PUT), Upper Magdalena Valley (VSM), San Jacinto (SIN), Tumaco (TUM) and Uraba (URA). In addition, estimated values were used for 27 sites, mainly in the eastern parts. Most of the data are from northeastern and central parts, while the data density is poor in the eastern parts. The mean value of resource base is $315 \mathrm{GJ}$ while the recoverable part is estimated to be $31 \mathrm{GJ}$.

The maps in the left and right panels of Figure 6 illustrate respectively the regional distributions per unit area of resource base (RBUA) and recoverable resources (RRUA). In this figure, as in the previous cases, the blue dots indicate locations of observational data while crosses indicate locations of estimated values, these latter ones derived from spherical harmonic expansion of global heat flow data [38]-[41]. Note that resource base is higher than $200 \mathrm{GJ}$ all along the central parts, indicated as yellow shaded areas. However, the resource base with values higher than $300 \mathrm{GJ}$ are restricted to a narrow NE-SW trending belt, which is roughly coincident with the main magmatic belt of central Colombia. These are indicated as red shaded areas in the left panel. Similar trends can also be seen in the distribution of recoverable resources, illustrated in the right panel of Figure 6.
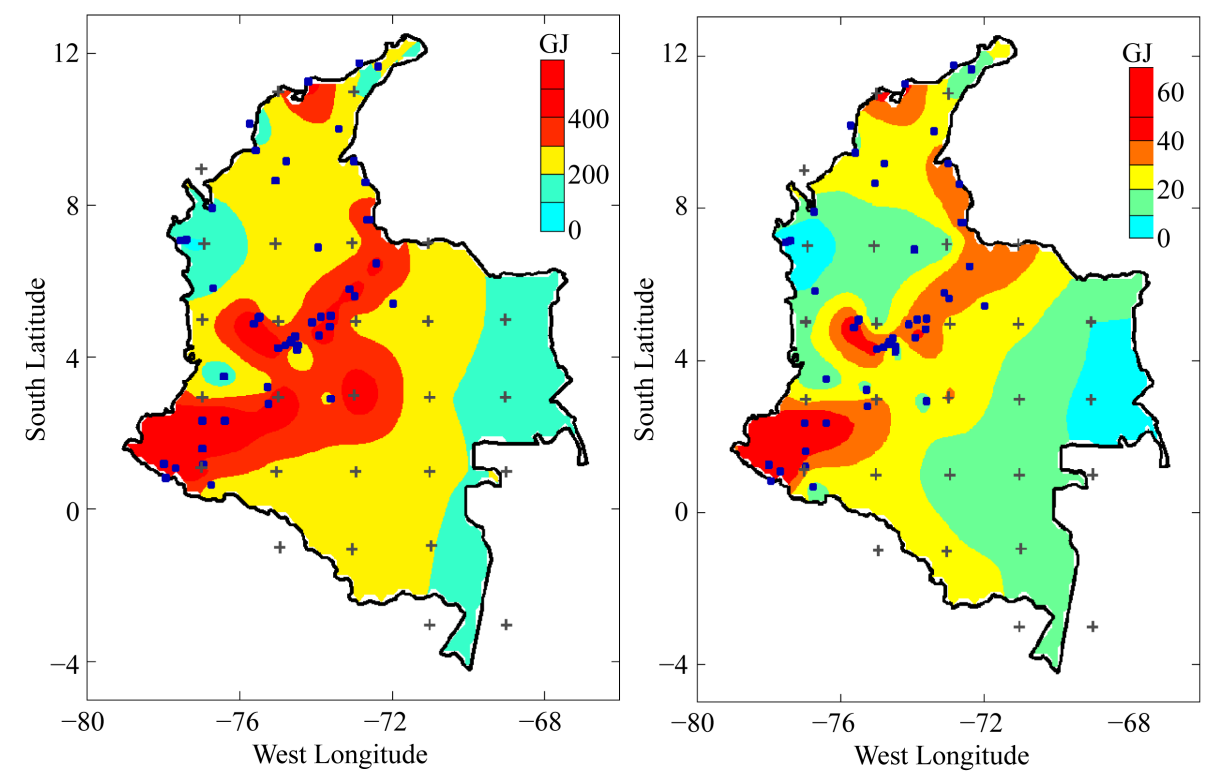

Figure 6. Distributions of geothermal resource base (left panel) and recoverable resources (right panel) in Colombia. Dots indicate locations of observational data and crosses indicate estimated values. 


\subsection{Ecuador}

The estimates of geothermal resources for Ecuador are based on data acquired in 41 localities. These include results of incremental temperature logs (CVL) for one site [52] and bottom-hole method (BHT) for 34 sites [30]. Also included are results of geochemical methods (GCL) for additional 10 sites [22]-[24]. In addition, estimated values were used for 8 sites, mainly in the eastern parts. Most of the data are from northeastern and central parts, while the data density is poor in the eastern parts. The mean value of resource base is $267 \mathrm{GJ}$ while the recoverable part is estimated to be 37 GJ. The maps in the left and right panels of Figure 7 illustrate respectively the regional distributions of resource base (RBUA) and recoverable resource (RRUA). As in the previous case, the blue dots indicate locations of observational data while crosses indicate locations of estimated values, these latter ones derived from spherical harmonic expansion of global heat flow data [38]-[41].

Note that resource base per unit area is higher than $200 \mathrm{GJ}$ in the northern parts. There are indications that occurrence of resource base with values higher than $300 \mathrm{GJ}$ are restricted to a narrow NE-SW trending belt. The relative location of this belt is roughly coincident with the main magmatic belt that extends into the cordilleran regions in the east. These are indicated as yellow and red shaded areas in the left panel. A similar trend can also be seen in the distribution of recoverable resources, illustrated in the right panel of Figure 7.

\subsection{Paraguay}

The estimates of geothermal resources for Paraguay are based on data acquired in 34 localities. These include results of bottom-hole method (BHT) applied to oil wells in the Chaco and Santa Cruz-Perija basins [30] [53]. In addition, estimated values were used for 8 sites, mainly in the eastern parts. Most of the data are from northeastern and central parts, while the data density is poor in the eastern parts. The mean value of resource base is 244 GJ while the recoverable part is estimated to be 24 GJ. The maps in the left and right panels of Figure 8 illustrate respectively the regional distributions of resource base (RBUA) and recoverable resource (RRUA), based on this data set. As in the previous case, the blue dots indicate locations of observational data while crosses indicate locations of estimated values, these latter ones derived from spherical harmonic expansion of global heat flow data [38]-[41]. Note that resource base per unit area is higher than $200 \mathrm{GJ}$ in the northern parts. There are indications that resource base with values higher than $300 \mathrm{GJ}$ are restricted to a narrow NW-SE trending belt. However, the anomaly does not seem to extend into the adjacent regions in Bolivia. Also, the general direction is different from that observed for resources in Colombia and Ecuador. Clearly, additional data is needed for a better understanding of the tectonic context of this anomaly. These are indicated as yellow and red shaded areas in the left panel. A similar trend can also be seen in the distribution of recoverable resources, illustrated in the right panel of Figure 8. However, the maximum value of recoverable resource is no more than 30 GJ.
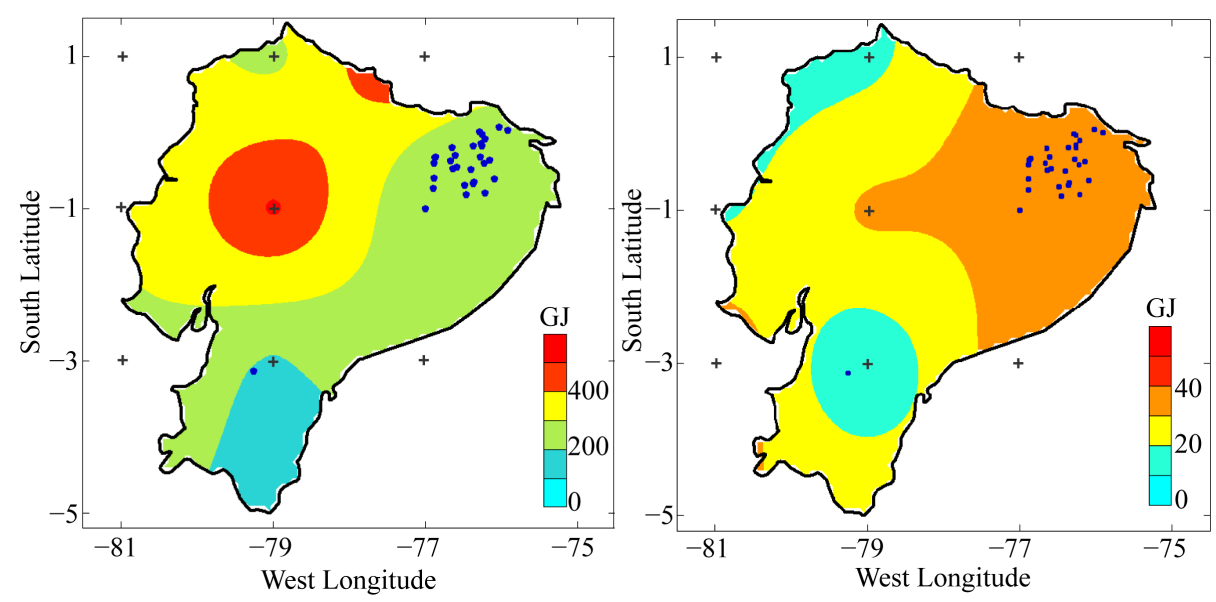

Figure 7. Distributions of geothermal resource base (left panel) and recoverable resources (right panel) in Ecuador. Dots indicate locations of observational data and crosses indicate estimated values. 

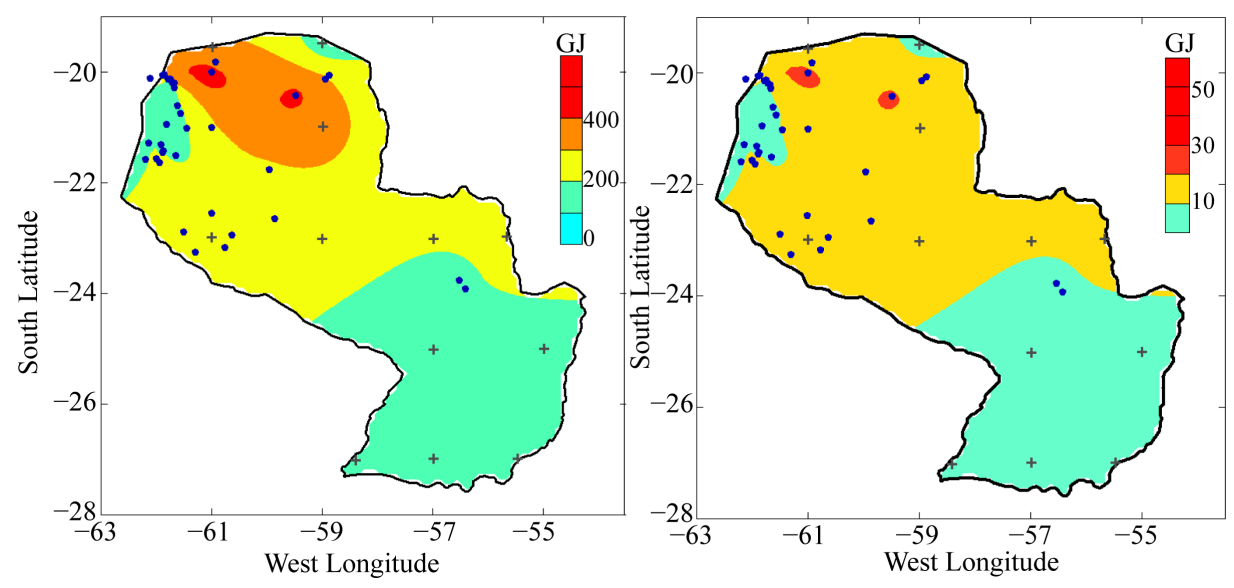

Figure 8. Distributions of geothermal resource base (left panel) and recoverable resources (right panel) in Paraguay. Dots indicate locations of observational data and crosses indicate estimated values.

\subsection{Peru}

The estimates of geothermal resources for Peru are based on data acquired in 93 localities. These include results of incremental temperature logs (CVL) and underground mine measurements at 16 sites and bottom-hole method (BHT) for 5 sites [48] [52] [54]. Also included are geothermal gradient values reported by [55] [56] for 46 sites in the Marañon basin. Results of geothermal measurements carried out using Bullard-type probes for 19 sites in Lake Titicaca [57] are also considered as complementary data. Estimated values based spherical harmonic coefficients of global heat flow data [38]-[41] were used for 31 sites, mainly in the eastern parts. The mean value of resource base is $206 \mathrm{GJ}$ while the recoverable part is estimated to be $10 \mathrm{GJ}$. The maps in the left and right panels of Figure 9 illustrate respectively the regional distributions of resource base (RBUA) and recoverable resource (RRUA), based on this data set. As in the previous case, the blue dots in these maps indicate locations of observational data while crosses indicate locations of estimated values.

Referring to Figure 9 note that resource base per unit area is higher than 200 GJ mainly in the northern compared to southern parts. These are indicated as yellow and red shaded areas in the left panel. There are indications that resource base with values higher than $300 \mathrm{GJ}$ are restricted to a narrow east-west trending belt. High values of resources also seem to be present in the southernmost tip. A similar trend can also be seen in the distribution of recoverable resources, illustrated in the right panel of Figure 9. However, the maximum value of recoverable resource is no more than $30 \mathrm{GJ}$.

\subsection{Uruguay}

The estimates of geothermal resources for Peru are based on data acquired in 14 localities. These include results of temperature measurements in flowing wells (AQT method) in 7 localities [9] this work. Estimated values based spherical harmonic coefficients of global heat flow data [38]-[41] were used for 7 sites, mainly in the eastern parts. The mean value of resource base is $225 \mathrm{GJ}$ while the recoverable part is estimated to be $27 \mathrm{GJ}$. The maps in the left and right panels of Figure 10 illustrate respectively the regional distributions of resource base (RBUA) and recoverable resource (RRUA), based on this data set. As in the previous case, the blue dots in these maps indicate locations of observational data while crosses indicate locations of estimated values.

Referring to Figure 10 note that resource base per unit area is higher than 200 GJ mainly in the western parts. These are indicated as yellow and red shaded areas in the left panel. A similar trend can also be seen in the distribution of recoverable resources, illustrated in the right panel of Figure 10.

\subsection{Venezuela}

The estimates of geothermal resources for Venezuela are based on data acquired in 64 localities. Results of geochemical analyzes of thermal springs at 40 sites in the northern region, which were used in obtaining esti- 

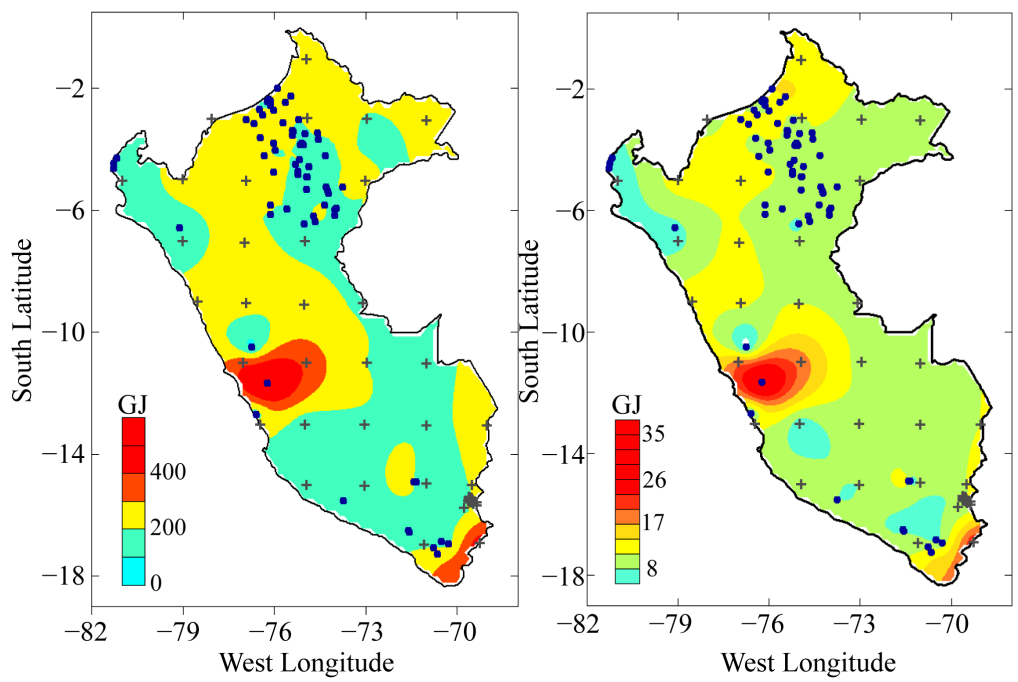

Figure 9. Distributions of geothermal resource base (left panel) and recoverable resource (right panel) in Peru. Dots indicate locations of observational data and crosses indicate estimated values.
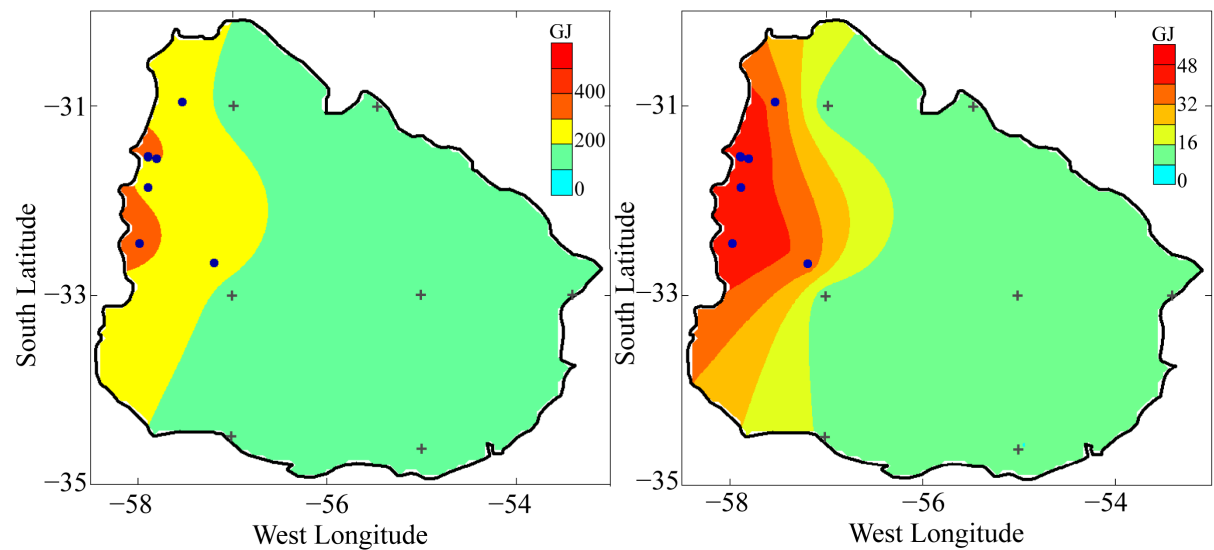

Figure 10. Distributions of geothermal resource base (left panel) and recoverable resources (right panel) in Uruguay. Dots indicate locations of observational data and crosses indicate estimated values.

mates of heat flow by the geochemical method [28]-[30]. There are two major problems with this data set. First, lack of observational data on subsurface temperatures makes the evaluation of the results of geochemical methods (GCL) a difficult task. Second, the data density is highly variable, since most of the thermal springs are situated along a narrow strip in the northernmost part of the country. In an attempt to minimize problems arising from the large variations in data density estimated values based on spherical harmonic coefficients of global heat flow data [38]-[41] were used for 24 sites, located mainly in the southern parts. The mean value of resource base is 324 GJ while the recoverable part is estimated to be 44 GJ. The maps in the left and right panels of Figure 11 illustrate respectively the regional distributions of resource base (RBUA) and recoverable resource (RRUA), based on this data set. As in the previous case, the blue dots in these maps indicate locations of observational data while crosses indicate locations of estimated values.

Referring to Figure 11 note that resource base per unit area is higher than $200 \mathrm{GJ}$ in the northern compared to southern parts. These are indicated as yellow and red shaded areas in the left panel. There are indications that resource base with values higher than $300 \mathrm{GJ}$ are restricted to a narrow southwest-northeast trending belt. This belt seems to be continuation of the similar belt identified in resource distribution of Colombia. A similar trend can also be seen in the distribution of recoverable resources, illustrated in the right panel of Figure 11. 

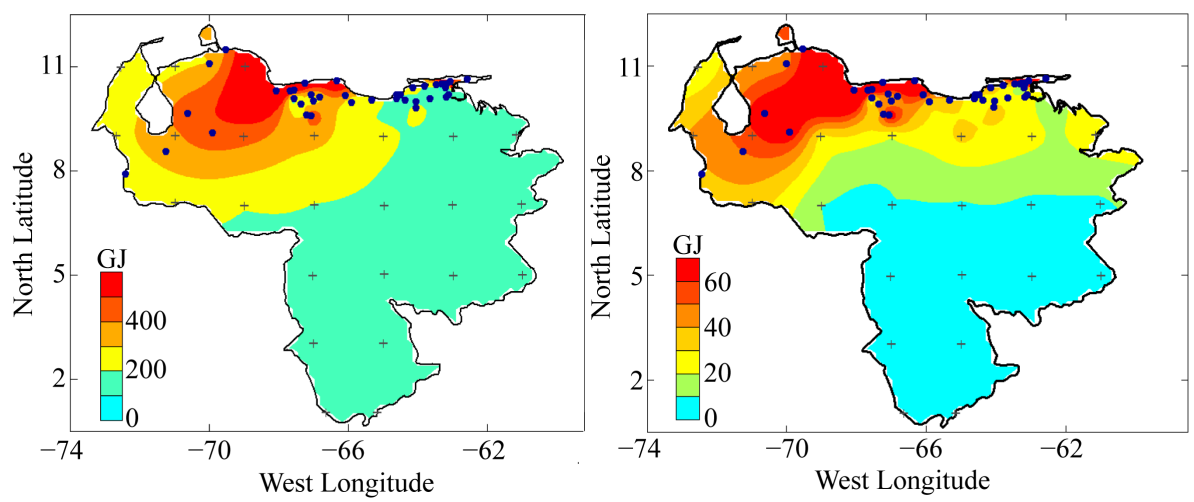

Figure 11. Distributions of geothermal resource base (left panel) and recoverable resources (right panel) in Venezuela. Dots indicate locations of observational data and crosses indicate estimated values.

\subsection{French Guiana, Guiana and Suriname}

Results of geothermal studies have not been reported for French Guiana, Guiana and Suriname. Hence, maps of resources distributions are not presented for these countries. Nevertheless, resource estimates based on estimated values are included in the data base for overall assessment.

\section{Discussion and Conclusions}

A summary of values obtained in assessments of resource base and recoverable resources is presented in Table 1 , for the thirteen countries of the continent. Estimates of total resource base can be obtained as product of values of areas in column 2 and resource base in column 4 . The highest value found for resource base per unit area (RBUA) is 499 GJ, for Chile. Relatively high values are also found for Argentina (352 GJ), Venezuela (324 GJ) and Colombia (315 GJ). Intermediate values of resource base are found for Ecuador (264 GJ), Bolivia (245 GJ), Uruguay (225 GJ) and Peru (206 GJ). The estimate for RBUA in Peru is lower than that expected for cordilleran regions. It is in contrast with evidences of extensive magmatic emplacements at shallow crustal levels and probably reflects lack of adequate observational data. The estimate of mean RBUA for Brazil is $178 \mathrm{GJ}$ but there are considerable regional variations. The remaining three countries in the northern part of the continent (French Guiana, Guiana and Suriname) are found to have values of RBUA less than 150 GJ.

Similar trends can also be observed for estimates of recoverable resources. Thus high values of recoverable resources are found for Argentina (79 GJ) and Chile (61 GJ). Values of recoverable resources in the intermediate range are found for Venezuela (44 GJ), Bolivia (41 GJ), Ecuador (37 GJ) and Colombia (31 GJ). Relatively low values of recoverable resources are found for Uruguay (27 GJ), Paraguay (24 GJ), Brazil (10 GJ) and Pe$\mathrm{ru}(10 \mathrm{GJ})$. The estimates of recoverable resources are found to be less than $10 \mathrm{GJ}$ French Guiana, Guiana and Suriname where geothermal manifestations have not been reported.

Integrated analysis of the results obtained for the different countries is useful in understanding the regional distribution of geothermal resources. The maps of Figure 12 illustrate the distributions of resource base (left panel) and recoverable resources (right panel) for the South American continent. Referring to the left panel of this figure, it is noted that resource base with values higher than $400 \mathrm{GJ}$ occur in areas comprising central and northern parts of Chile, southwest of Bolivia, west-central Argentina, southern Colombia and northwestern parts of Venezuela. Resource base with values in excess of $300 \mathrm{GJ}$ is present only in small isolated localities in the interior parts of the continent. In the context of tectono-thermal characteristics of the South American continent, this observation implies that high enthalpy resources in the western parts of the continent are almost all of deep crustal origin [58] [59].

The distributions of recoverable resources illustrated in the right panel of this figure reveal a quite different pattern. Recoverable resources, with values in the range of 20 to $40 \mathrm{GJ}$, are significant in several regions in the eastern parts of the continent. These include the sedimentary basins of the Amazon region in the north, Parnaiba basin in the northeast and western parts of Paraná basin in the south. As mentioned earlier recoverable resources are also significant in the southern state of Rio Grande do Sul. Low enthalpy resources are also present along 
Table 1. Estimates per unit area of resource base (RBUA) and recoverable resources (RRUA), for the thirteen countries in South America. $\mathrm{N}$ refers to number of localities used in resource assessments (numbers in brackets refer to wells with observational data).

\begin{tabular}{ccccc}
\hline Country & Area $\left(10^{3} \mathrm{~km}^{2}\right)$ & $\mathrm{N}$ & \multicolumn{2}{c}{ Resource $\left(\mathrm{GJ} / \mathrm{m}^{2}\right)$} \\
\cline { 3 - 4 } Argentina & 2790 & RBUA & 352 & RRUA \\
Bolivia & 1100 & $233(2941)$ & 245 & 41 \\
Brazil & 8480 & 52 & 178 & 10 \\
Chile & 760 & 930 & 499 & 31 \\
Colombia & 1200 & 56 & 315 & 37 \\
Ecuador & 270 & 51 & 267 & 7 \\
French Guiana & 91 & - & 147 & 7 \\
Guiana & 215 & - & 144 & 24 \\
Paraguay & 407 & 35 & 244 & 10 \\
Peru & 1290 & 87 & 206 & 9 \\
Suriname & 163 & - & 146 & 27 \\
Uruguay & 178 & 7 & 225 & 44 \\
Venezuela & 912 & 40 & 324 & \\
\hline
\end{tabular}
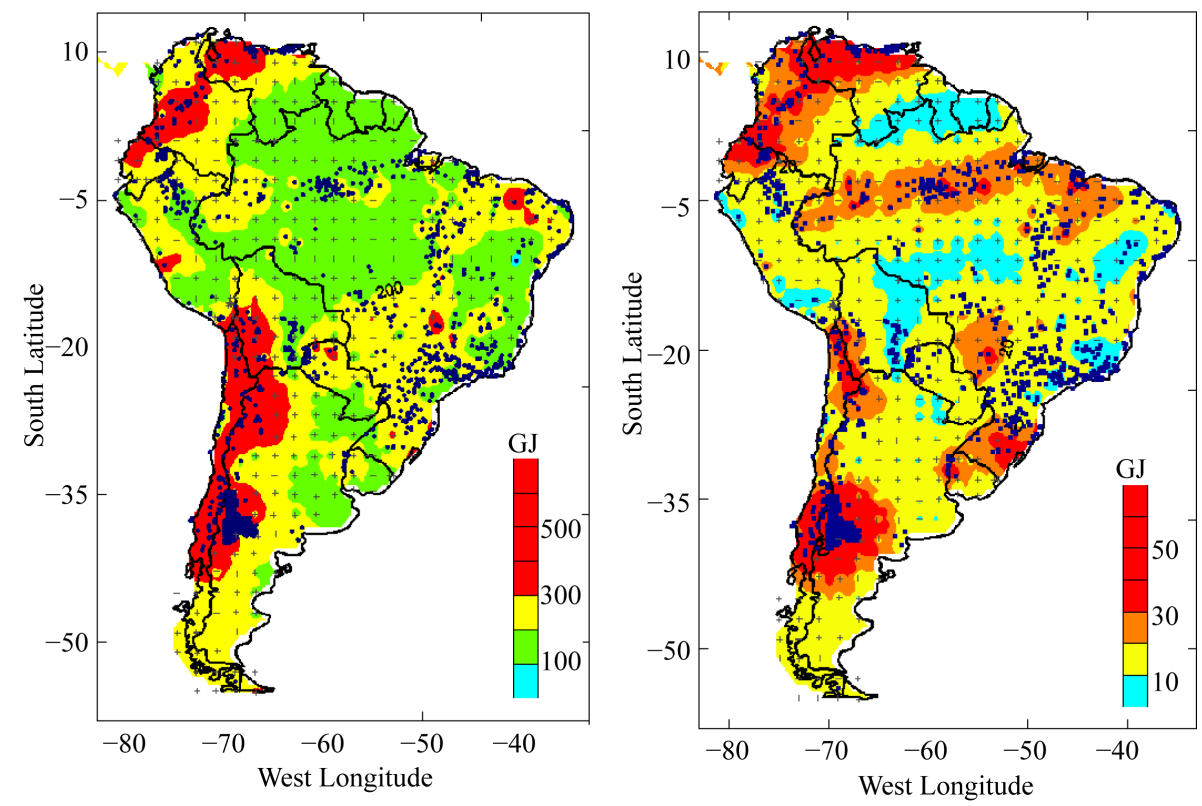

Figure 12. Distributions of geothermal resource base (left panel) and recoverable resources (right panel) in the South American continent. Dots indicate locations of observational data and crosses indicate estimated values.

narrow strips bordering the Paraná River in Uruguay and Argentina, in the eastern parts of the continent.

It is clear that the results of the present work have led to improvements in evaluation of the spatial distributions of both low and high enthalpy geothermal resources in the South American continent. In particular, it is now possible to understand better the relations between the crustal layer of origin of surface manifestations of geothermal fluids and the resource base in geothermal areas. The integrated resource base for upper crust is estimated to be of the order of $10 \mathrm{TJ}$. This value is significantly different from that obtained in previous studies. 


\section{Acknowledgements}

The present work was carried out as part of Ph.D. thesis project of the first author. The second author is recipient of a scholarship granted by National Research Council of Brazil (CNPq-Project No. 301865/2008-6).

\section{References}

[1] Battocletti, L. (1999) Database of Geothermal Resources in Latin American \& the Caribbean. Report for Sandia National Laboratories, Bob Lawrence \& Associates Inc., Contract No. AS-0989.

[2] Cardoso, R.R., Hamza, V.M. and Alfaro, C. (2010) Geothermal Resource Base for South America: A Continental Perspective. Proceedings of the World Geothermal Congress, Bali, 25-29 April 2010.

[3] Huttrer, G.W. (2001) The Status of World Geothermal Power Generation 1995-2000. Geothermics, 30, 7-27. http://dx.doi.org/10.1016/S0375-6505(00)00042-0

[4] Barbier, E. (2002) Geothermal Energy Technology and Current Status: An Overview. Renewable and Sustainable Energy Reviews, 6, 3-65. http://dx.doi.org/10.1016/S1364-0321(02)00002-3

[5] Lund, J.W. and Freeston, D.H. (2001) World-Wide Direct Uses of Geothermal Energy 2000. Geothermics, 30, 29-68. http://dx.doi.org/10.1016/S0375-6505(00)00044-4

[6] Miranda, F.J. and Pesce, A.H. (1997) Argentina Geothermal Resources: New Trends in Development. GRC Transactions, 21, 337-339.

[7] Pesce, A.H. (1995) Argentina Country Update. Proceedings of the World Geothermal Congress, Florence, 35-43.

[8] Pesce, A.H. (2000) Argentina Country Update. Proceedings of the World Geothermal Congress, Kyushu-Tohoku, 28 May-10 June 2000, 35-43.

[9] Pesce, A.H. (2005) Argentina Country Update. Proceedings of the World Geothermal Congress, Antalya, 24-29 April 2005.

[10] Delgadillo, T.Z. (1997) Situación Actual de Los Proyectos Geotérmicos en Bolivia. Seminar Desarrollo de los Recursos Geotérmicos en América Latina y el Caribe, Comisión Económica para América Latina y el Caribe (CEPAL), Santiago del Chile, 10 al 12 de noviembre de 1997.

[11] Hamza, V.M., Eston, S.M. and Araújo, R.L.C. (1978) Geothermal Energy Prospects in Brazil: A Preliminary Analysis. Pure and Applied Geophysics, 117, 180-195. http://dx.doi.org/10.1007/BF00879745

[12] Hamza, V.M. and Eston, S.M. (1983) Assessment of Geothermal Resources of Brazil-1981. Zentralblatt fur Geologie und Palaontologie, 1, 128-155.

[13] Eston, S.M. and Hamza, V.M. (1984) Energia Geotérmica no Brasil: Avaliação de Recursos, Avanços Tecnológicos e Perspectivas de Utilização. Simpósio Brasileiro Sobre Técnicas Exploratórias Aplicadas á Geologia, 1, 109-132.

[14] Hamza, V.M., Frangipani, A. and Becker, E.A. (1990) Development of Geothermal Projects in Brazil: Current State and Perspectives. Proceedings of the International Seminar on Geothermal Perspectives for Latin America and Caribe, 37-52.

[15] Hamza, V.M., Gomes, A.J.L. and Ferreira, L.E.T. (2005) Status Report on Geothermal Energy Developments in Brazil. Proceedings of the World Geothermal Congress, Antalya, 24-29 April 2005.

[16] Hamza, V.M., Cardoso, R.R., Gomes, A.J.L. and Alexandrino, C.H. (2010) Brazil: Country Update. Proceedings of the World Geothermal Congress, Bali, 25-29 April 2010.

[17] Lahsen, A. (1988) Chilean Geothermal Resources and Their Possible Utilization. Geothermics, 17, 401-410. http://dx.doi.org/10.1016/0375-6505(88)90068-5

[18] Muñoz, M. and Hamza, V.M. (1993) Heat Flow and Temperature Gradients in Chile. Studia geophysica et geodaetica, 37, 315-348.

[19] Lahsen, A., Sepúlveda, F., Rojas, J. and Palacios, C. (2005) Present Status of Geothermal Exploration in Chile. Proceedings of the World Geothermal Congress, Antalya, 24-29 April 2005.

[20] Alfaro, C., Bernal, N., Ramírez, G. and Escovar, R. (2000) Colombia, Country Update. Proceedings of the World Geothermal Congress, Kyushu, 28 May-10 June 2000, 45-50.

[21] Alfaro, C., Alvarado, I., Quintero, W., Hamza, V.M., Vargas, C. and Briceño, L.A. (2011) Preliminary Map of Geothermal Gradients in Colombia. Proceedings of the 12th Colombian Geological Congress, Paipa, 1-6.

[22] Almeida, E. (1988) Los Recursos Geotérmicos del Ecuador Continental. Unpublished Interim Report, INECEL, Ecuador.

[23] Beate, B. and Salgado, R. (2005) Geothermal Country Update for Ecuador, 2000-2005. Proceedings of the World Geothermal Congress, Antalya, 24-29 April 2005. 
[24] Beate, B. and Salgado, R. (2010) Geothermal Country Update for Ecuador, 2005-2010. Proceedings of the World Geothermal Congress, Bali, 25-29 April 2010.

[25] Diaz, H. and Guillermo, N. (1988) Potential for Developing Small Geothermal Power Stations in Peru. Geothermics, 17, 381-390. http://dx.doi.org/10.1016/0375-6505(88)90066-1

[26] Parodi, I.A. (1975) Feasibility of the Development of the Geothermal Energy in Perú-1975. Proceedings of the Lawrence Berkeley Laboratory-Second United Nations Symposium, Berkeley, 20-29 May 1975, 227-231.

[27] Almandoz, A.H. and Rojas, J.J. (1988) Geothermal Prospects in the Central Region of Sucre State, Venezuela. Geothermics, 17, 369-375. http://dx.doi.org/10.1016/0375-6505(88)90064-8

[28] Urbani, P.F. (1987) A Review of Venezuelan Geothermics. Brazilian Geophysical Journal, 5, 153-164.

[29] Hamza, V.M. and Muñoz, M. (1996) Heat Flow Map of South America. Geothermics, 25, 599-646. http://dx.doi.org/10.1016/S0375-6505(96)00025-9

[30] Hamza, V.M., Silva Dias, F.J.S., Gomes, A.J.L. and Delgadilho Terceros, Z.G. (2005) Numerical and Functional Representations of Regional Heat Flow in South America. Physics of the Earth and Planetary Interiors, 152, 223-256. http://dx.doi.org/10.1016/i.pepi.2005.04.009

[31] Beck, A.E. (1965) Techniques of Measuring Heat Flow on Land. In: Lee, W.H.K., Ed., Terrestrial Heat Flow, Monograph No. 8, American Geophysical Union, Washington DC, 24-57.

[32] Bullard, E.C. (1939) Heat Flow in South Africa. Proceedings of the Royal Society A, 173, 474-502. http://dx.doi.org/10.1098/rspa.1939.0159

[33] Carvalho, H.S. and Vacquier, V. (1977) Method for Determining Terrestrial Heat Flow in Oil Fields. Geophysics, 42, 584-593. http://dx.doi.org/10.1190/1.1440729

[34] Gomes, A.J.L. and Hamza, V.M. (2005) Geothermal Gradient and Heat Flow in the State of Rio de Janeiro. RevistaBrasileira de Geofisica, 23, 325-347. http://dx.doi.org/10.1590/S0102-261X2005000400001

[35] Santos, J., Hamza, V.M. and Shen, P.Y. (1986) A Method for Measurement of Terrestrial Heat Flow Density in Water Wells. Revista Brasileira de Geofísica, 4, 45-53.

[36] Swanberg, C.A. and Morgan, P. (1978) The Linear Relation between Temperatures Based on the Silica Content of Groundwater and Regional Heat Flow: A New Heat Flow Map of the United States. Pure and Applied Geophysics, 117, 227-241. http://dx.doi.org/10.1007/BF00879749

[37] Hurter, S.J. (1986) The Use of Chemical Geothermometry and Heat Loss Models in Estimating Terrestrial Heat Flow for Low Temperature Hydrothermal Systems. Revista Brasileira de Geofísica, 6, 33-42.

[38] Chapman, D. and Pollack, H. (1975) Global Heat Flow: A New Look. Earth and Planetary Science Letters, 28, 23-32. http://dx.doi.org/10.1016/0012-821X(75)90069-2

[39] Pollack, H.N., Hurter, S.J. and Johnson, J.R. (1993) Heat Flow from the Earth’s Interior: Analysis of the Global Data Set. Reviews of Geophysics, 31, 267-280. http://dx.doi.org/10.1029/93RG01249

[40] Cardoso, R.R. (2006) Analytic Representation of the Global Thermal Field by the Method of Spherical Harmonics (in Portuguese). Master's Thesis, Observatório Nacional-MCT, Rio de Janeiro, 1-147.

[41] Hamza, V.M., Cardoso, R.R. and Ponte Neto, C.F. (2008) Spherical Harmonic Representation of Earth's Conductive Heat Flow. International Journal of Earth Sciences, 97, 205-226. http://dx.doi.org/10.1007/s00531-007-0254-3

[42] Mooney, W.D., Laske, G. and Masters, T.G. (1998) Crust 5.1: A Global Crustal Model at $5^{\circ} \times 5^{\circ}$. Journal of Geophysical Research, 103, 727-747. http://dx.doi.org/10.1029/97JB02122

[43] Bassin, C., Laske, G. and Masters, G. (2000) The Current Limits of Resolution for Surface Wave Tomography in North America. Eos, Transactions American Geophysical Union, 81, F897.

[44] Muffler, L.J.P. and Cataldi, R. (1978) Methods for Regional Assessment of Geothermal Resources. Geothermics, 7, 53-89. http://dx.doi.org/10.1016/0375-6505(78)90002-0

[45] Čermak, V., Bodri, L., Rybach, L. and Buntebarth, G. (1990) Relationship between Seismic Velocity and Heat Production: Comparison of Two Sets of Data and Test of Validity. Earth and Planetary Science Letters, 99, 48-57. http://dx.doi.org/10.1016/0012-821X(90)90069-A

[46] Uyeda, S., Watanabe, T. and Volponi, F. (1978) Report of Heat Flow Measurements in San Juan and Mendoza, Argentina. Bulletin of the Earthquake Research Institute, 53, 165-172.

[47] Sigismondi, M.E. (2012) Estudio de la deformaciôn litosférica de la cuenca Neuquina: estructura termal, datos de gravedad y sísmica de reflexiôn. Ph.D. Thesis, Universidad de Buenos Aires, Buenos Aires, 1-367.

[48] Henry, S.G. (1981) Terrestrial Heat Flow Overlying the Andean Subduction Zone. Ph.D. Thesis, University of Michigan, Ann Arbour.

[49] Henry, S.G. and Pollack, H.N. (1988) Terrestrial Heat Flow above the Andean Subduction Zone in Bolivia and Peru. 
Journal of Geophysical Research, 93, 15153-15162. http://dx.doi.org/10.1029/JB093iB12p15153

[50] Uyeda, S., Watanabe, T., Kausel, E., Kubo, M. and Yashiro, Y. (1978) Report of Heat Flow Measurements in Chile. Bulletin of the Earthquake Research Institute, 53, 131-163.

[51] Sass, J.H., Munroe, R.J. and Moses Jr., T.H. (1974) Heat Flow from Eastern Panama and Northeastern Colombia. Earth and Planetary Science Letters, 21, 134-142. http://dx.doi.org/10.1016/0012-821X(74)90046-6

[52] Uyeda, S., Watanabe, T., Ozasayama, Y. and Ibaragi, K. (1980) Report of Heat Flow Measurements in Peru and Ecuador. Bulletin of the Earthquake Research Institute, 55, 55-74.

[53] Kuhn, C.A. (1991) The Geological Evolution of the Paraguayan Chaco. Ph.D. Thesis, Texas Technical University, Austin, 185.

[54] Uyeda, S. and Watanabe, T. (1982) Terrestrial Heat Flow in Western South America. Tectonophysics, 83, 63-70. http://dx.doi.org/10.1016/0040-1951(82)90007-5

[55] Fuentes, R. (1984) Estudio de las temperaturas de la cuenca Marañón. Unpublished Report 300-629-84, Dept. of Technology, Div. of Exploration and Exploitation, Petróleos del Perú.

[56] Ocola, L. (1985) Flujo calórico en el nor-oriente peruano: Cuenca Marañón. III Simposio Sudamericano de COGEODATA, Tema No. 20, Lima.

[57] Sclater, J.G., Vacquier, V. and Rohrhirsch, J.H. (1970) Terrestrial Heat Flow Measurements on Lake Titicaca, Peru. Earth and Planetary Science Letters, 8, 45-54. http://dx.doi.org/10.1016/0012-821X(70)90098-1

[58] Vieira, F.P. (2011) Global Representation of Mantle Heat Flow (in Portuguese). Master's Thesis, National Observatory, Rio de Janeiro, 1-67.

[59] Vieira, F.P. and Hamza, V.M. (2011) Global Heat Flow: Comparative Analysis Based on Experimental Data and Theoretical Values. Proceedings of the 12th International Congress of Brazilian Geophysical Society, Rio de Janeiro, 15-18 August 2011, 1-6. 
Scientific Research Publishing (SCIRP) is one of the largest Open Access journal publishers. It is currently publishing more than 200 open access, online, peer-reviewed journals covering a wide range of academic disciplines. SCIRP serves the worldwide academic communities and contributes to the progress and application of science with its publication.

Other selected journals from SCIRP are listed as below. Submit your manuscript to us via either submit@scirp.org or Online Submission Portal.
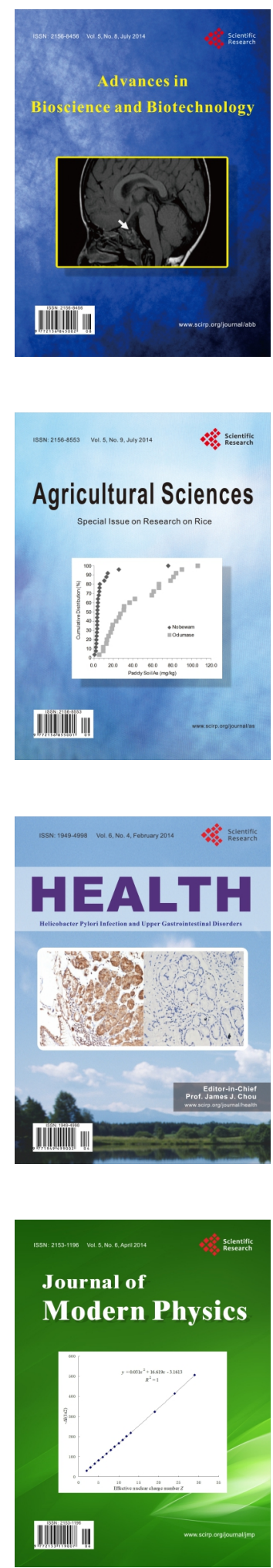
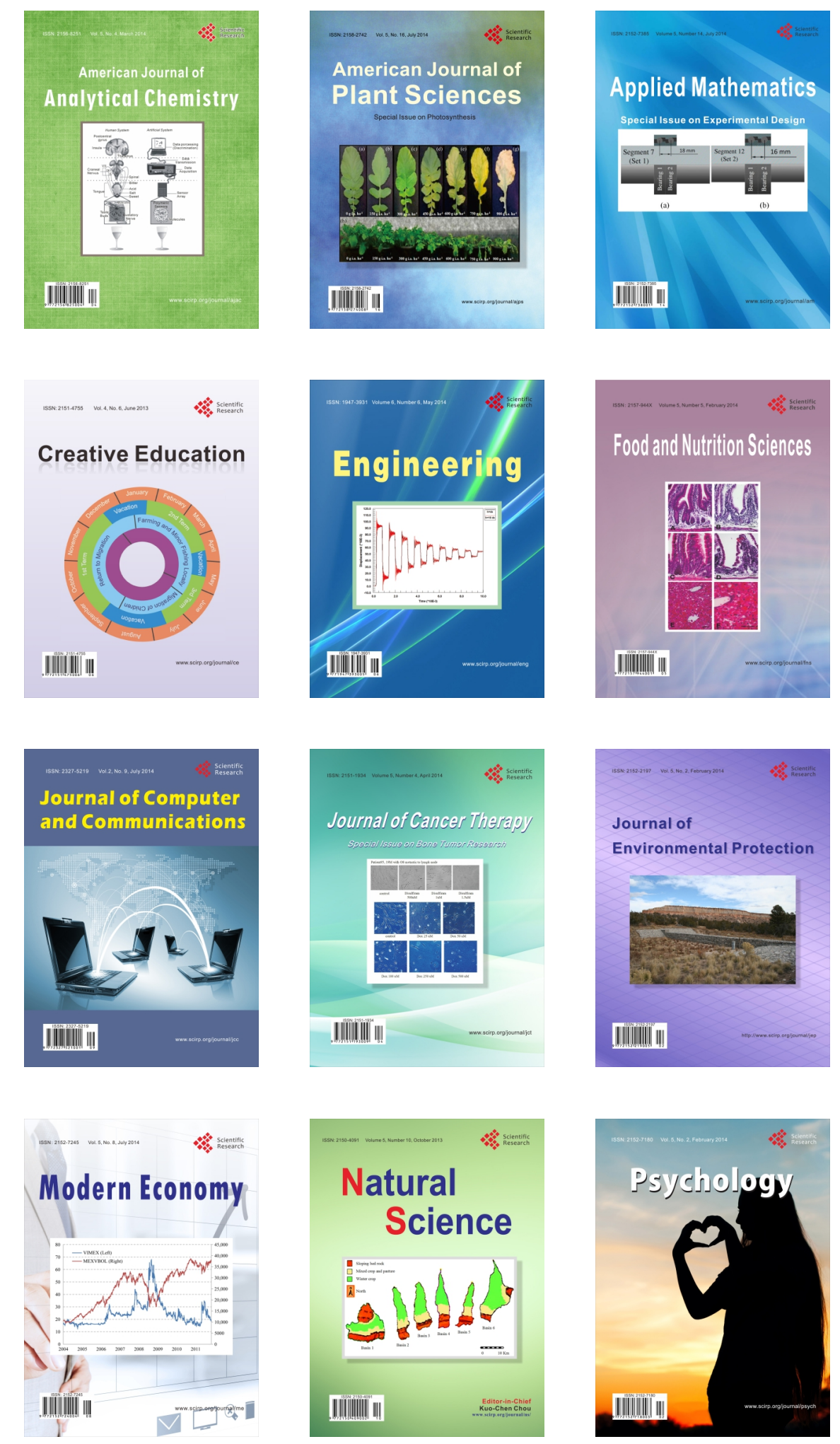